\title{
EFFECT OF HYDROPHILIC AND HYDROPHOBIC POLYMER MATRIX ON THE TRANSDERMAL DRUG DELIVERY OF ETHINYLESTRADIOL AND MEDROXYPROGESTERONE ACETATE
}

\author{
SHIKHA BAGHEL CHAUHAN ${ }^{*}$, TANVEER NAVED ${ }^{b}$, NAYYAR PARVEZ
}

\author{
aDepartment of Pharmaceutics, Amity Institute of Pharmacy, Amity University, Noida, Uttar Pradesh, India, bepartment of \\ Pharmaceutics, Amity Institute of Pharmacy, Amity University, Noida, Uttar Pradesh, India, 'Department of Pharmacy, School of Medical \\ and Allied Sciences, Galgotias University, Greater Noida, UP, India \\ Email: shikha.pharma@gmail.com
}

Received: 21 Sep 2018, Revised and Accepted: 12 Dec 2018

\begin{abstract}
Objective: The aims of the present study were to develop different matrix patches with various ratios of hydrophilic and hydrophobic polymer combinations such as ethyl cellulose (EC) and polyvinylpyrrolidone (PVP) and eudragit RL 100 (ERL) and eudragit RS 100 (ERS) containing ethinylestradiol and medroxyprogesterone acetate and to perform physicochemical characterization and in vitro permeation studies through rat skin.

Methods: Six formulations (F1 to F6) were developed by varying the concentration of both hydrophilic and hydrophobic polymer and keeping the drug load constant. Physical parameters and drug excipient interaction studies were evaluated in all the formulations. In vitro, skin permeation profiles of ethinylestradiol and medroxyprogesterone acetate from various formulations were simultaneously characterized in a thermostatically controlled modified Franz Diffusion cell. The physicochemical compatibility of the drug and the polymers was studied by differential scanning calorimetry.

Results: The results suggested no physicochemical incompatibility between the drug and the polymers. In vitro permeation studies were performed by using Franz diffusion cells, patches coded as F3 (ethyl cellulose: polyvinylpyrrolidone, 7.5:2.5) and F6 (eudragit RL 100 (ERL) and eudragit RS 100 (ERS), 8:2) can be chosen for further in vivo studies. The results followed Higuchi kinetics $(\mathrm{r}=0.9953-0.9979)$, and the mechanism of release was diffusion mediated. Based on physicochemical and in vitro skin permeation studies of 85.64\% (for F3) and 88.62\% (for F6) of ethinylestradiol and medroxyprogesterone acetate.
\end{abstract}

Conclusion: The developed transdermal patches are stable, non-irritating and had increased efficacy of ethinylestradiol and medroxyprogesterone acetate and therefore had a good potential for antifertility treatment.

Keywords: Transdermal, Antifertility, Ethinylestradiol, Medroxyprogesterone acetate, Polyvinylpyrrolidone, Ethylcellulose, Eudragit RL 100 (ERL) and eudragit RS 100 (ERS)

(C) 2019 The Authors. Published by Innovare Academic Sciences Pvt Ltd. This is an open access article under the CC BY license (http://creativecommons.org/licenses/by/4.0/] DOI: http://dx.doi.org/10.22159/ijap.2019v11i1.29886

\section{INTRODUCTION}

In the early 1960s, shortly after the introduction of oral contraceptives, the first case reports appeared describing venous thrombosis and pulmonary emboli in women using oral contraceptives as a method for birth control. Later, myocardial infarction and stroke were also found to be associated with the use of oral contraceptives. The absolute risk of venous thrombosis has been reported to increase from a baseline risk of less than 1 per 10,000 women-years to 3 to 4 per 10,000 women-years during use of OCs [1]

Oral contraceptives containing estrogen-progestin combinations have been associated with an increased risk of deep vein thrombosis and subsequent pulmonary embolism, collectively referred to as venous thromboembolism (VTE) [2-6].

A large number of Transdermal Drug Delivery (TDD) systems have been widely used to treat a variety of diseases since it has many advantages over oral contraceptive pills. TDD systems are able to provide the continuous supply of drug through the skin, avoiding peaks and troughs as found with oral pills.

Losses of bioavailability due to first-pass hepatic metabolism and enzymatic degradation in the gastrointestinal tract that are seen with oral drug administration are avoided, which makes it possible to use lower doses of the drug to achieve the therapeutic effect [7].

Postmenopausal HRT with oral or transdermal estrogen alone has been effective in alleviating vasomotor symptoms of menopause and also in reducing cardiovascular mortality risks and osteoporosis, but concomitant progestin therapy would protect against endometrial hyperplasia and carcinoma without compromising the benefits of estrogen therapy [8].
Therefore, it was decided to plan formulation and development of transdermal patch containing ethinylestradiol and medroxyprogesterone acetate using various polymers and plasticizers to overcome the side effects associated with oral contraceptives pills and have an alternative to the patients suffering from daily dosing problems associated with oral contraceptives.

There are reports describing the use of eudragit RL 100 (ERL) and eudragit RS 100 (ERS)transdermal delivery systems as well as other dosage forms for controlled release of drugs [9] ERL is freely permeable to water, whereas ERS is slightly permeable [10]. These transdermal delivery systems are neither extremely hydrophobic nor extremely hydrophilic. Therefore, varying the ratio of these polymers in the composition of the films provides control of drug release characteristics [11].

The aims of the present study were to develop different matrix patches with various ratios of hydrophilic and hydrophobic polymer combinations such as ethyl cellulose (EC) and polyvinylpyrrolidone (PVP) and eudragit RL 100 (ERL) and eudragit RS 100 (ERS) containing ethinylestradiol and medroxyprogesterone acetate and to perform physicochemical characterization and in vitro permeation studies through rat skin. The purpose was to provide the delivery of the drug at a controlled rate across intact skin to improve bioavailability and hypertension control for the longer period from transdermal patches.

\section{MATERIALS AND METHODS}

\section{Materials}

Ethinylestradiol was obtained as a gift sample from Cipla pharmaceuticals, Ltd., Mumbai and medroxyprogesterone acetate 
was obtained from Tokyo Chemical Industry Co., Ltd, Japan. Eudragit RL 100 (ERL) and eudragit RS 100 (ERS), Hydroxypropyl methyl cellulose (HPMC), ethylcellulose (EC) and polyvinylpyrrolidone (PVP) were obtained from Central Drug House Pvt. Ltd., New Delhi. Other materials used in the study (sodium chloride, disodium hydrogen phosphate, potassium dihydrogen phosphate etc) were purchased from Central Drug House Pvt. Ltd., New Delhi and were of analytical grade. Double Distilled water was used throughout the study. Other materials used in the study (chloroform, sodium hydroxide, phosphoric acid, diethyl ether, were of analytical grade. Double-distilled water was used throughout the study.

\section{Investigation of physicochemical compatibility of drug and polymer}

The physicochemical compatibility between ethinylestradiol and medroxyprogesterone acetate and polymers used in the patches was studied by using differential scanning calorimetry (DSC, PerkinElmer-Pyris 6 DSC, Salem, MA). In DSC analysis, the samples were weighed ( $5 \mathrm{mg}$ ), hermetically sealed in flat-bottom aluminum pans, and heated over a temperature range of 50 to $250{ }^{\circ} \mathrm{C}$ in an atmosphere of nitrogen $(20 \mathrm{ml} / \mathrm{min})$ at a constant increasing rate of $10{ }^{\circ} \mathrm{C} / \mathrm{min}$. The thermograms obtained for ethinylestradiol and medroxyprogesterone acetate, polymers, and physical mixtures of ethinylestradiol and medroxyprogesterone acetate with polymers were compared.

The infrared (IR) spectra were recorded using an FTIR spectrophotometer (FTIP-800, Biorad, Munich, Germany) by the KBr pellet method and spectra were recorded in the wavelength region between 4000 and $400 \mathrm{~cm}-1$. The spectra obtained for ethinylestradiol and medroxyprogesterone acetate polymers and physical mixtures of ethinylestradiol and medroxyprogesterone acetate with polymers were compared.

\section{Preparation of transdermal films}

The matrix-type transdermal patches containing ethinylestradiol and medroxyprogesterone acetate were prepared using different ratios of EC: PVP and ERL 100:ERS 100 (table 1). The polymers in different ratios were increased to a total weight of $400 \mathrm{mg}$ and dissolved in chloroform. Ethinylestradiol and medroxyprogesterone acetate was added slowly to the polymer solution and mixed thoroughly to obtain a uniform solution. Di-n-butyl-phthalate was used as a plasticizer. The polymeric solution of drug was poured onto the mercury surface $\left(25 \mathrm{~cm}^{2}\right)$ and dried at room temperature in a dust-free environment. After $24 \mathrm{~h}$, the films were cut into a $5 \mathrm{~cm}^{2}$ piece, and a backing membrane of polypropylene film was glued on. The transdermal films were stored in a desiccator until further use.

Table 1: Composition of ethinylestradiol and medroxyprogesterone acetate transdermal Drug Delivery systems

\begin{tabular}{|c|c|c|c|c|c|c|c|}
\hline \multirow[t]{4}{*}{ S. No. } & \multirow[t]{2}{*}{ Ingredients } & \multicolumn{6}{|c|}{ Formulation codes } \\
\hline & & F1 & F2 & F3 & F4 & F5 & F6 \\
\hline & Ethinylestradiol (mg) & 0.35 & 0.35 & 0.35 & 0.35 & 0.35 & 0.35 \\
\hline & Medroxyprgesterone acetate (mg) & 2.14 & 2.14 & 2.14 & 2.14 & 2.14 & 2.14 \\
\hline 1 & Ratio of ethylcellulose (EC): polyvinylpyrroplidone (PVP) & $9: 1$ & $8: 2$ & $7.5: 2.5$ & - & - & - \\
\hline 2 & Ratio of eudragit RL 100 (ERL): eudragit RS 100 (ERS) & - & - & - & 5:5 & $7: 3$ & $8: 2$ \\
\hline 3 & Propylene glycol $(\% \mathrm{w} / \mathrm{w})$ & 30 & 30 & 30 & 30 & 30 & 30 \\
\hline 4 & DMSO & 7 & 7 & 7 & 7 & 7 & 7 \\
\hline
\end{tabular}

EC: ethyl cellulose, PVP: polyvinylpyrrolidone, HPMC: hydroxypropyls methylcellulose, PG: propylene Glycol, DMSO: Dimethyl sulfoxide, all values are expressed as mean $\pm \mathrm{SD}(\mathrm{n}=10)$

\section{Evaluation of physicochemical properties of patches}

\section{Weight variation}

Weight variation was studied by individually weighing 10 randomly selected patches. Such determination was performed for each formulation [12].

\section{Drug content}

The patch $\left(1 \mathrm{~cm}^{2}\right)$ was cut and added to a beaker containing $100 \mathrm{ml}$ of phosphate buffered $\mathrm{pH}$ 7.4. The medium was stirred (500 rpm) with teflon coated magnetic bead for $5 \mathrm{~h}$. The contents were filtered using whatman filter paper, and the filtrate was analyzed by U. V. spectrophotometer at $280 \mathrm{~nm}$ for the drug content against the blank solution [12, 24].

\section{Flatness}

Three longitudinal strips were cut out from each film: 1 from the center, 1 from the left side, and 1 from the right side. The length of each strip was measured and the variation in length because of nonuniformity in flatness was measured by determining percent constriction, with $0 \%$ constriction equivalent to $100 \%$ flatness [12]

\section{Folding endurance}

Folding endurance was determined by repeatedly folding the film at the same place until it broke. The number of times the film could be folded at the same place without breaking was the folding endurance value [12, 24].

\section{Percentage of moisture content}

The films were weighed individually and kept in a desiccator containing activated silica at room temperature for $24 \mathrm{~h}$. Individual films were weighed repeatedly until they showed a constant weight. The percentage of moisture content was calculated as the difference between the initial and final weight with respect to final weight [13]
Percentage of moisture content $=\mathrm{X}-\mathrm{Y} / \mathrm{Y} \times 100$

Where, $\mathrm{X}=$ initial weight, $\mathrm{Y}=$ final weight.

\section{Percentage of moisture uptake}

A weighed film kept in a desiccator at room temperature for $24 \mathrm{~h}$ was taken out and exposed to $84 \%$ relative humidity (a saturated solution of aluminum chloride) in a desiccator until a constant weight for the film was obtained. The percentage of moisture uptake was calculated as the difference between final and initial weight with respect to initial weight [14].

Percentage of moisture uptake $=\mathrm{X}-\mathrm{Y} / \mathrm{Y} \times 100$

Where, $\mathrm{X}=$ initial weight, $\mathrm{Y}=$ final weight.

\section{In vitro skin permeation studies}

The in vitro release was carried out with the semipermeable membrane using open-ended cylinder. The cylinder consists of two chambers, the donor and the receptor compartment. The donor compartment was open at the top and was exposed to an atmosphere. The temperature was maintained at $37 \pm 0.5{ }^{\circ} \mathrm{C}$ and receptor compartment was provided with sampling port. The diffusion medium used was phosphate buffer ( $\mathrm{pH}$ 7.4). The drugcontaining patch with support of backing membrane was kept in the donor compartment and it was separated from the receptor compartment by the semipermeable membrane. The semipermeable membrane was previously soaked for $24 \mathrm{~h}$ in phosphate buffer $\mathrm{(pH} 7.4)$ the receptor compartment containing $300 \mathrm{ml}$ phosphate buffer (pH 7.4) in a beaker was maintained at $37 \pm 0.5^{\circ} \mathrm{C}$ and stirred at $50 \mathrm{rpm}$ with magnetic beads operated by a magnetic stirrer. A sample of 1 $\mathrm{ml}$ was withdrawn at predetermined time intervals and replaced with fresh buffer. The concentration of drug was determined by spectrophotometrically at $280 \mathrm{~nm}$. The cumulative amounts of drug permeated per square centimeter of patches were plotted against time $[15,25]$. 
Simultaneous spectrophotometric determination of ethinylestradiol and medroxyprogesterone acetate

Ethinylestradiol absorbs at $\lambda \max$ of Medroxyprogesterone acetate and vice versa. Thus, a simple spectrophotometric method using no prior separation has been developed for the analysis of ethinylestradiol and Medroxyprogesterone acetate in phosphate buffer (pH7.4) by Vierordt's equation in our laboratory $(15,25)$

\section{Ex vivo skin permeation studies}

The in vitro skin permeation studies were carried out using the dorsal section of full thickness skin from wistar rats weighing between (200-250 g) hairs were removed by shaving from the dorsal area one day before the test. All the experimental procedures were approved by the Institutional Animal Ethics Committee (IAEC). All the experimental procedures were carried out accordance with the committee for the purpose of control and supervision of experiment on animal guidelines (129/2013/CPCSEA). Wistar rat's hairs were removed by shaving from the dorsal area one day before the test. The transdermal patches were firmly pressed on the centre of the rat skin. Once adhesion to the skin surface had been confirmed, the skin was quickly mounted on the diffusion tube which acted as the donor compartment. $100 \mathrm{ml}$ of phosphate buffer of $\mathrm{pH}$ 7.4 taken in a beaker, which acted as the receptor compartment to maintain the sink condition. The donor compartment was kept in contact with the receptor compartment and the receptor compartment was stirred magnetically during the study [15]. After every $1 \mathrm{~h}$ sample $(1 \mathrm{ml})$ was withdrawn at predetermined time intervals and replaced with fresh buffer. The concentration of drug was determined by U. V. spectrophotometrically at $280 \mathrm{~nm}$ [15].

\section{RESULTS AND DISCUSSION}

Investigation of physicochemical compatibility of drug and polymer

The physicochemical compatibility between the drugs and polymers used in the patches was studied by using differential scanning calorimetry (DSC). The sample was heated between $30^{\circ} \mathrm{C}$ and $300^{\circ} \mathrm{C}$ at the rate of $10{ }^{\circ} \mathrm{C} / \mathrm{min}$ in an atmosphere of nitrogen $(20 \mathrm{ml} / \mathrm{min})$. The thermograms obtained for the drug, polymers, physical mixture of drugs with polymers and formulation (patch) were compared.

The DSC results suggest that the drug and polymers are compatible as found in fig. 1. Wade and Weller reported that ethylcellulose (EC), polyvinylpyrrolidone (PVP), eudragit RL 100 (ERL), eudragit RS 100 (ERS), and other common polymers are popular in controlled-and sustained release matrix-type patches because of their compatibility with several drugs [16].

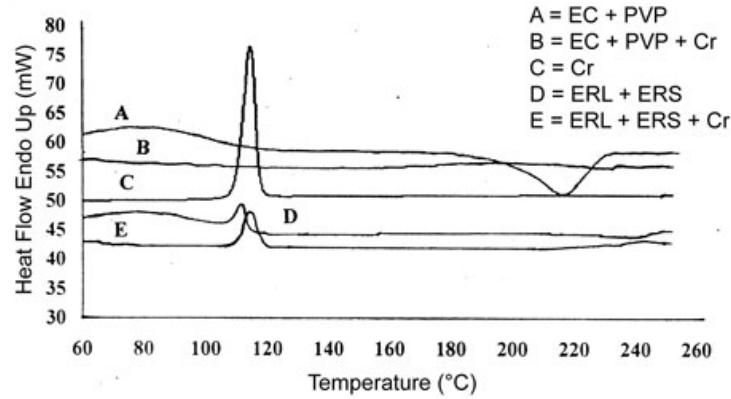

Fig. 1: DSC thermograms of drugs, polymers, and the physical mixtures. $\mathrm{Cr}$ indicates drug substances

\section{Physicochemical characterization of patches}

The results of the physicochemical characterization of the patches are shown in table 2 . The weights ranged between $26.43 \mathrm{mg}$ and $26.88 \mathrm{mg}$, which indicates that different batches' patch weights were relatively similar. Good uniformity of drug content among the batches was observed with all formulations and ranged from $96.26 \%$ to $96.87 \%$. The results indicate that the process employed to prepare patches in this study was capable of producing patches with uniform drug content and minimal patch variability. The flatness study showed that all the formulations had the same strip length before and after their cuts, indicating $100 \%$ flatness.

Thus, no amount of constriction was observed; all patches had a smooth, flat surface; and that smooth surface could be maintained when the patch was applied to the skin. Folding endurance test results indicated that the patches would not break and would maintain their integrity with general skin folding when applied.

Moisture content and moisture uptake studies indicated that the increase in the concentration of hydrophilic polymer was directly proportional to the increase in moisture content and moisture uptake of the patches. The moisture content of the prepared formulations was low, which could help the formulations remain stable and reduce brittleness during long-term storage. The moisture uptake of the formulations was also low, which could protect the formulations from microbial contamination and reduce bulkiness $[17,24]$.

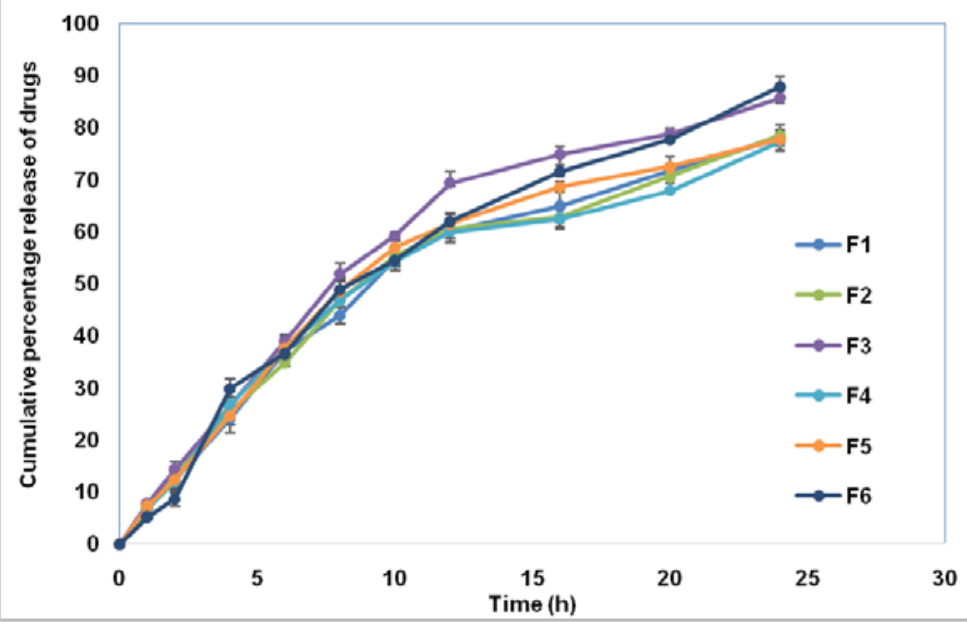

Fig. 2: Release profiles of ethinylestradiol and medroxyprogesterone acetate from formulations F1-F6. All values are expressed as mean $\pm S D(n=3)$ 
Table 2: Physicochemical properties of transdermal patches*

\begin{tabular}{|c|c|c|c|c|c|c|c|c|c|c|}
\hline $\begin{array}{l}\text { S. } \\
\text { No. }\end{array}$ & $\begin{array}{l}\text { Formul } \\
\text { ation } \\
\text { code }\end{array}$ & $\begin{array}{l}\text { Meanthickne } \\
\text { ss (mm) }\end{array}$ & $\begin{array}{l}\text { Moistureco } \\
\text { ntent }(\%)\end{array}$ & $\begin{array}{l}\text { Moistureab } \\
\text { sorption } \\
(\%)\end{array}$ & $\begin{array}{l}\text { Drugconten } \\
\text { t (\%) }\end{array}$ & $\begin{array}{l}\text { Foldingen } \\
\text { durance }\end{array}$ & $\begin{array}{l}\text { Weight } \\
\text { (mg) }\end{array}$ & $\begin{array}{l}\text { Tensile } \\
\text { strength } \\
(\mathrm{gm} / 10 \\
\left.\mathrm{cm}^{2}\right)^{*}\end{array}$ & $\begin{array}{l}\text { Moisture } \\
\text { absorption } \\
(\%)\end{array}$ & $\begin{array}{l}\text { Water } \\
\text { vapourtransmis } \\
\text { sion rate } \\
\mathrm{Gm} / \mathrm{cm}^{2} / 72 \mathrm{~h} \\
\end{array}$ \\
\hline 1 & F1 & $0.026 \pm 0.002$ & $2.134 \pm 0.010$ & $2.174 \pm 0.023$ & $96.54 \pm 0.36$ & $105 \pm 2.6$ & $26.43 \pm 0.16$ & $15.13 \pm 0.23$ & $2.574 \pm 0.023$ & $0.01680 \pm 0.002$ \\
\hline 2 & F2 & $0.026 \pm 0.006$ & $2.283 \pm 0.013$ & $2.321 \pm 0.011$ & $96.55 \pm 0.24$ & $95 \pm 2.4$ & $26.87 \pm 0.18$ & $14.96 \pm 0.35$ & $2.321 \pm 0.011$ & $0.01676 \pm 0.005$ \\
\hline 3 & F3 & $0.025 \pm 0.005$ & $2.106 \pm 0.024$ & $2.643 \pm 0.021$ & $96.87 \pm 0.28$ & $102 \pm 5.6$ & $26.50 \pm 0.16$ & $15.44 \pm 0.17$ & $2.643 \pm 0.021$ & $0.01692 \pm 0.006$ \\
\hline 4 & $\mathrm{~F} 4$ & $0.025 \pm 0.004$ & $2.328 \pm 0.021$ & $2.232 \pm 0.016$ & $98.45 \pm 0.27$ & $110 \pm 4.9$ & $26.22 \pm 0.17$ & $15.36 \pm 0.27$ & $2.632 \pm 0.016$ & $0.01706 \pm 0.003$ \\
\hline 5 & F5 & $0.024 \pm 0.002$ & $2.432 \pm 0.010$ & $2.528 \pm 0.015$ & $97.29 \pm 0.75$ & $119 \pm 5.2$ & $25.95 \pm 0.26$ & $15.58 \pm 0.12$ & $2.528 \pm 0.015$ & $0.01704 \pm 0.002$ \\
\hline 6 & F6 & $0.026 \pm 0.003$ & $2.514 \pm 0.021$ & $2.628 \pm 0.015$ & $96.26 \pm 0.84$ & $111 \pm 3.7$ & $26.88 \pm 0.14$ & $14.32 \pm 0.27$ & $2.316 \pm 0.011$ & $0.01694 \pm 0.005$ \\
\hline
\end{tabular}

*All values are expressed as mean \pm SD $(n=10)$.

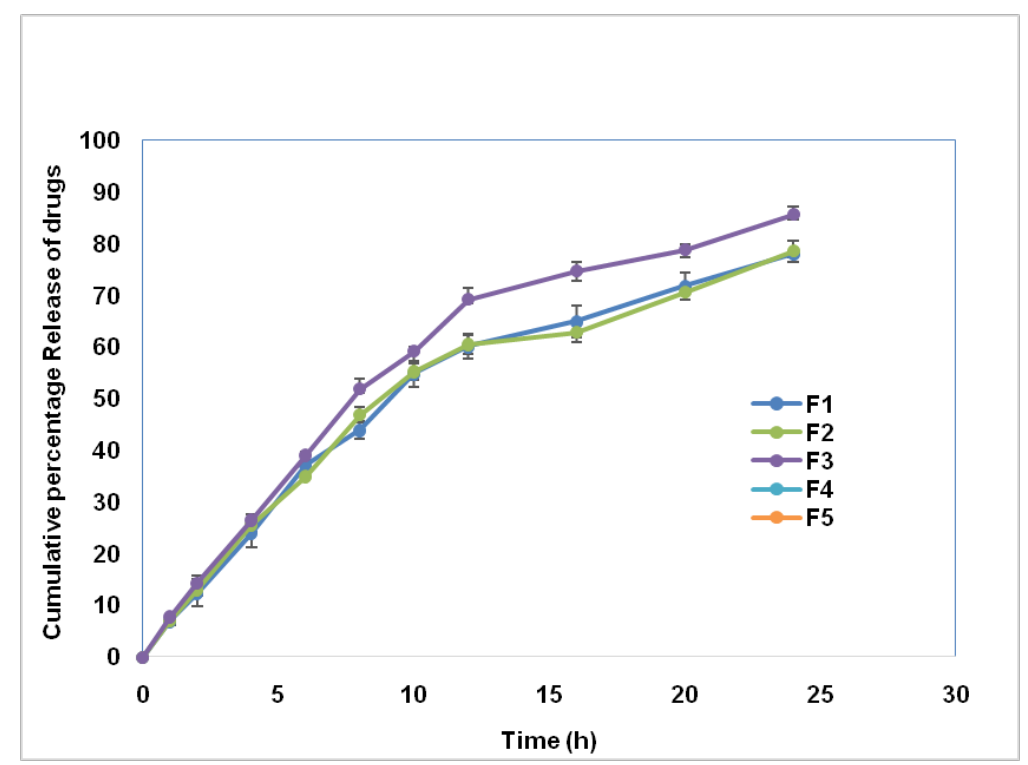

Fig. 3: In vitro skin permeation profile of ethinylestradiol and medroxyprogesterone acetate from transdermal patches with different proportions of Ethylcellulose: polyvinylpyrrolidone, data are mean $\pm S E(n=6)$

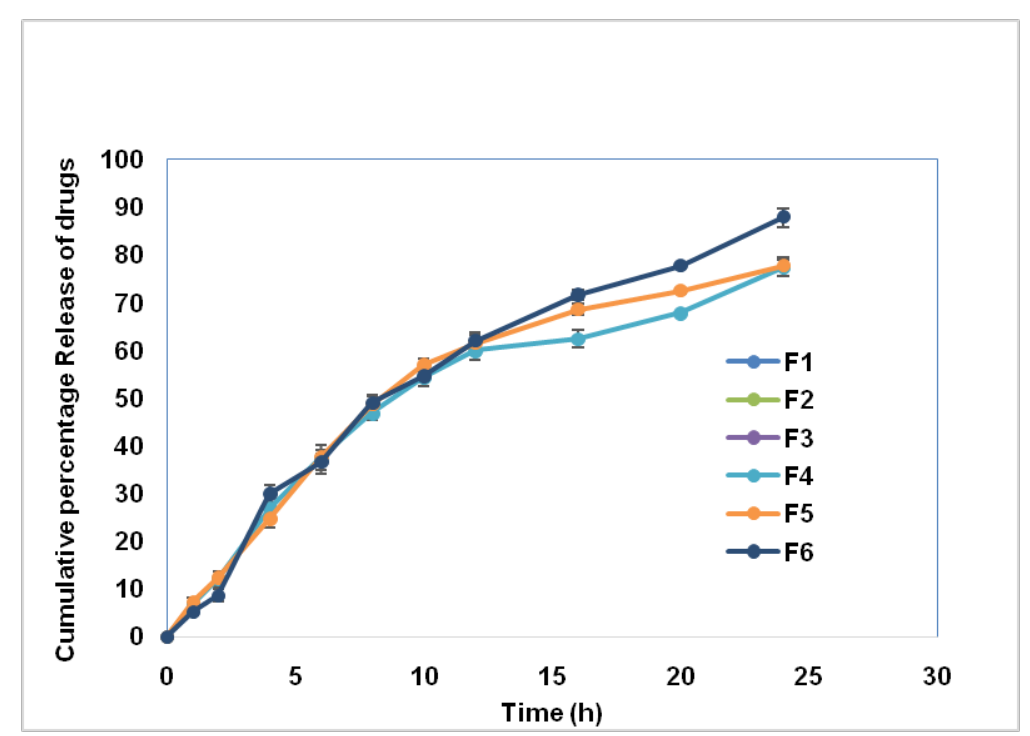

Fig. 4: In vitro skin permeation profile of ethinylestradiol and medroxyprogesterone acetate from transdermal patches with different proportions of ERL 100: ERS 100 Data are mean $\pm S E(n=6)$

\section{In vitro skin permeation studies}

The in vitro release profile is an important tool that predicts in advance how a drug will behave in vivo [18]. The results of in vitro skin permeation studies of ethinylestradiol and medroxyprogesterone acetate from transdermal patches are shown in fig. 2 , fig. 3 and fig. 4. The cumulative amount of drug released from formulations $\left(1 \mathrm{~cm}^{2}\right) \mathrm{F} 3$ and F6 was high when compared with 
release from other formulations. When the cumulative amount of drug permeated per square centimeter of patches through rat skin was plotted against time, the permeation profiles of the drug followed mixed zero-order/first-order kinetics. The in vitro release profiles of the formulations did not fit into zero-order kinetics ( $\mathrm{r} 2=$ 0.9206-0.9282) or first-order kinetics ( $\mathrm{r} 2=0.6615-0.6782$ ). However, the release profile of the formulated patches followed Higuchi's equation ( $2=0.9953-0.9979$ ), which indicates that the permeation of the drug from the patches was governed by a diffusion mechanism. Since many release processes can be represented by a coupling of a Fickian and non-Fickian mechanism, Ritger and Peppas introduced the power law equation Mt $/ \mathrm{M} \infty=\mathrm{Ktn}$ to characterize the controlled-release behavior of a drug from polymer matrices [19]. The value of $n$ can be calculated from the slope of In Mt/Mo vs in $t$ and can be indicative of the operating release mechanism. The $n$ values $(0.5022<n>0.5268)$ obtained by this equation indicated that the amount of drug released by Fickian diffusion predominated with all formulations. In this context, the results obtained from the Fickian mechanism support the results of Higuchi's equation and the theory that the patches release the drug by a diffusion-dominated mechanism.

The in vitro permeation experiment indicated that when the hydrophilic polymer concentration increased, the amount of drug permeation increased. As described by Rao and Diwan, initial rapid dissolution of the hydrophilic polymers occurs when the patch is in contact with the hydrated skin, resulting in the accumulation of high amounts of the drug on the skin surface and thus leading to the saturation of the skin with drug molecules at all times [20,22].

Unlike the formulations F1, F2, F4, and F5, the formulations F3 and F6 achieved a high cumulative amount of drug permeation at the end of $24 \mathrm{~h}$. The F3 and F6 formulations were found to have similar permeability coefficients and the highest levels of release. Based on physicochemical and in vitro release experiments, F3 and F6 were chosen for further in vivo studies.

Table 3: Regression coefficient $\left(r^{2}\right)$ values of kinetic model of formulation F1-F6

\begin{tabular}{lllll}
\hline Formulation code & $\begin{array}{l}\text { Zero order } \\
\text { regression value }\left(\mathbf{R}^{\mathbf{2}}\right)\end{array}$ & $\begin{array}{l}\text { First order } \\
\text { regression value }\end{array}$ & $\begin{array}{l}\text { Higuchi } \\
\text { regression value }\end{array}$ & Koresmeyar peppas (slope) \\
\hline F1 & 0.987 & 0.936 & 0.923 & 0.985 \\
F2 & 0.932 & 0.934 & 0.923 & 1.206 \\
F3 & 0.938 & 0.931 & 0.937 & 1.022 \\
F4 & 0.936 & 0.935 & 0.922 & 1.024 \\
F5 & 0.949 & 0.934 & 0.944 & 1.023 \\
F6 & 0.934 & 0.931 & 0.926 & 1.024 \\
\hline
\end{tabular}

It is evident that all the formulations F1-F6 followed Higuchi kinetics, as the regression coefficients ( $\left.\mathrm{r}^{2}\right)$ values (table 3) for the release of both ethinylestradiol and medroxyprogesterone acetate are closer to 1 and more than the $\left(\mathrm{r}^{2}\right)$ values obtained after treating the data through zero order or first order kinetics.

\section{Skin irritation test}

The skin irritation test of the transdermal formulations F3 and F6 showed a skin irritation score (erythema and edema) of less than 2 (table 4). According to Draize et al., compounds producing scores of 2 or less are considered negative (no skin irritation) $[21,23,26]$. Hence, the developed transdermal formulations are free of skin irritation.

Table 4: Visual scores of skin irritation amongst various groups

\begin{tabular}{lllll}
\hline Group & I & II & III & IV \\
\cline { 2 - 5 } & Control (No treatment) & Blank (Blank patch) & Medicated (Medicated patch) & Formalin (0.8\% aq. Solution) \\
\hline Eythema & $0.00 \pm 0.00$ & $1.167 \pm 0.408^{* *}$ & $1.50 \pm 0.548^{* *}$ & $3.333 \pm 0.516$ \\
Edema & $0.00 \pm 0.00$ & $1.167 \pm 0.753^{* *}$ & $1.333 \pm 0.816^{* *}$ & $3.167 \pm 0.753$ \\
\hline
\end{tabular}

All values are reported as (mean value \pm SEM) $(n=6)$, **represents $\mathrm{P}<0.01$ (very significant) in comparison to group IV

\section{CONCLUSION}

The ethinylestradiol and medroxyprogesterone acetate transdermal patches developed in this study have great utility and are a viable option for effective and controlled management of antifertility. However, pharmacodynamics and pharmacokinetic evaluation of these systems in human volunteers is necessary to confirm these findings.

\section{ACKNOWLEDGMENT}

We are thankful to Amity University, Noida, Uttar Pradesh for providing us the facility to carry out the research studies. Last but not the least, to almighty God for providing inspiration and motivation for doing the research.

\section{AUTHORS CONTRIBUTIONS}

All the authors have contributed equally

\section{CONFLICT OF INTERESTS}

There is no conflict of interest to declare

\section{REFERENCES}

1. Vandenbroucke JP, Rosing J, Bloemenkamp KW, Middeldorp S, Helmerhorst FM, Bouma BN, et al. Oral contraceptives and the risk of venous thrombosis. N Engl J Med 2001;344:1527-35.
2. World Health Organization. Venous thromboembolic disease and combined oral contraceptives: results of an international multicentre case-control study. WHO collaborative study of cardiovascular disease and steroid hormone contraception. Lancet 1995;346:1575-82.

3. Gomes MP, Deitcher SR. Risk of venous thromboembolic disease associated with hormonal contraceptives and hormone replacement therapy: a clinical review. Arch Intern Med 2004;164:1965-76.

4. Jick H, Jick SS, Gurewich V, Myers MW, Vasilakis C. Risk of idiopathic cardiovascular death and nonfatal venous thromboembolism in women using oral contraceptives with differing progestagen components. Lancet 1995;346:1589-93.

5. Jick H, Kaye JA, Vasilakis Scaramozza C, Jick SS. Risk of venous thromboembolism among users of third generation oral contraceptives compared with users of oral contraceptives with levonorgestrel before and after 1995: cohort and casecontrol analysis. Br Med J 2000;321:1190-5.

6. World Health Organization. Effect of different progestagens in low oestrogen oral contraceptives on the venous thromboembolic disease. WHO collaborative study of cardiovascular disease and steroid hormone contraception. Lancet 1995;346:1582-8.

7. Samisoe G. Transdermal hormone therapy: gels and patches. Climacteric 2004;7:347-56. 
8. Sendag F, Terek MC, Karadadas N. Sequential combined transdermal and oral postmenopausal hormone replacement therapies: effects on bleeding patterns and endometrial histology. Arch Gynecol Obstet 2001;265:209-13.

9. Thassu D, Vyas SP. Controlled transdermal mucolytic delivery system. Drug Dev Ind Pharm 1991;17:561-76.

10. Wade A, Weller PJ. Handbook of pharmaceutical excipients. Washington DC: American Pharmaceutical Publishing Association; 1994. p. 362-6.

11. Panigrahi L, Pattnaik S, Ghosal SK. The effect of $\mathrm{pH}$ and organic ester penetration enhancers on skin permeation kinetics of terbutaline sulfate from pseudo-latex-type transdermal delivery systems through mouse and human cadaver skins. AAPS PharmSciTech 2005;6:E167-73.

12. Arora P, Mukherjee P. Design, development, physicochemical, and in vitro and in vivo evaluation of transdermal patches containing diclofenac diethylammonium salt. J Pharm Sci 2002;91:2076-89.

13. Gupta R, Mukherjee B. Development and in vitro evaluation of diltiazem hydrochloride transdermal patches based on povidoneethyl cellulose matrices. Drug Dev Ind Pharm 2003;29:1-7.

14. Beckett AH, Stenlake JB. editors. Practical Pharmaceutical Chemistry. New Delhi: CBC Publishers and Distributors; 1998. p. 284.

15. Goodman M, Barry BW. Action of penetration enhancers on human skin as assessed by the permeation of model drugs 5 fluorouracil and estradiol.1. Infinite dose technique. J Invest Dermatol 1988;91:323-7.

16. Wade A, Weller PJ. Handbook of pharmaceutical excipients. Washington DC. American Pharmaceutical Publishing Association; 1994. p. 362-6.

17. Mutalik S, Udupa N. Glibenclamide transdermal patches: physicochemical, pharmacodynamic, and pharmacokinetic evaluations. J Pharm Sci 2004;93:1577-94.
18. Katayose S, Kataoka K. Water-soluble polyion complex associates of DNA and poly(ethylene glycol)-poly(L-lysine) block copolymer. Bioconjug Chem 1997;8:702-7.

19. Ritger PL, Peppas NA. A simple equation for description of solute release, I: Fickian and non-fickian release from nonswellable devices in the form of slabs, spheres, cylinders or discs. J Controlled Release 1987;5:23-36.

20. Rao PR, Diwan PV. Formulation and in vitro evaluation of polymeric films of diltiazem hydrochloride and indomethacin for transdermal administration. Drug Dev Ind Pharm 1998;24:327-36.

21. Draize JH, Woodward G, Calvery HO. Methods for the study of irritation and toxicity of substances applied topically to the skin and mucous membranes. J Pharmacol Exp Ther 1944;82:377-90.

22. Hardainiyan SW, Kumar KR, Nandy BC, Saxena RI. Design, formulation and in vitro drug release from transdermal patches containing imipramine hydrochloride as the model drug. Int J Pharm Pharm Sci 2017;9:220-5.

23. Das A, Ahmed AB. Formulation and evaluation of transdermal patch of indomethacin containing patchouli oil as natural penetration enhancer. Asian J Pharm Clin Res 2017;10:320-5.

24. Chauhan SB, Naved T. Formulation and development of transdermal drug delivery system of ethinylestradiol and medroxyprogesterone acetate for antifertility treatment. Int J ChemTech Res 2017;10:1164-71.

25. Chauhan SB, Naved T. Formulation and Development of transdermal drug delivery system of antifertility drugs using the combination of polymers. Int J Pharma Bio Sci 2017;8:30-5.

26. Soujanya C, Satya BL, Reddy ML, Manogna K, Prakash PR, Ramesh A. Formulation and in vitro and in vivo evaluation of transdermal patches of lornoxicam using natural permeation enhancers. Int J Pharm Pharm Sci 2014;6:282-6. 